as distance) is decisive despite the regulations, which are couched as a series of alternatives. ${ }^{2}$ Decisions are made by lay officers interpreting a medical report which pays insufficient attention to assessment of mobility. ${ }^{3}$ This study therefore measured not only aspects of the mobility of holders of the allowance but also the collective opinions of a group of assessors. The results should interest organisations representing disabled people. ${ }^{4}$

Most subjects walked more than the $100 \mathrm{~m}$ quoted in cases turned down on appeal. They were, however, studied under less stressful and more representative conditions than when being examined for the mobility allowance. The wide scatter of results confirms the variability of assessments and the need to rationalise the system for making the award. It is impossible to set a limiting value for any parameter but the likelihood of an applicant being successful increases as distance, speed, and time of walking decrease. I have therefore suggested three categories bounded by distances $(120 \mathrm{~m}$, $240 \mathrm{~m}$, and $360 \mathrm{~m}$ ) and speeds $(20 \mathrm{~m} / \mathrm{min}, 34 \mathrm{~m} / \mathrm{min}$, and $43 \mathrm{~m} / \mathrm{min})$ which might be the basis of a points system. Other parameters of mobility-for example, energy expenditure-would also have to be considered and weighted.

The Department of Health and Social Security should commission an independent evaluation of methods of assessing mobility, which would make examinations for the mobility allowance more objective and thereby reduce criticism of this allowance and examining doctors.

$1 \mathrm{McGavin}$ CR, Gupta SP, McHardy GJR. Twelve-minute walking test for assessing disability in chronic bronchitis. $\mathrm{Br}$ Med $\mathrm{F}$ 1976; ; $822-3$.

2 Department of Health and Social Security. Mobility allowance. Notes for medical practitioners. London: DHSS, 1979. (NI 213.)

3 Oglesby PR. Review of attendance allowance and mobility allowance procedures and of medical adjudication. London: DHSS, 1983.

4 RADAR. Mobility and attendance allowances: an analysis of DHSS statistics from 1983. London: RADAR, 1984.

(Accepted 28 October 1985)

Rehabilitation Studies Unit, Princess Margaret Rose Hospital, Fairmilehead, Edinburgh EH10 7ED

J HUNTER, FRCPED, consultant physician in rehabilitation medicine

\section{Treatment of chronic painful diabetic neuropathy with intravenous lidocaine infusion}

Treatment of painful diabetic neuropathy is still a major clinical problem. ${ }^{1-3}$ Two uncontrolled studies showed that intravenous lidocaine infusion was a promising new treatment for painful diabetic and non-diabetic neuropathy ${ }^{45}$ In a randomised, double blind crossover study we investigated the effect of intravenous lidocaine infusion on the symptoms and signs of painful diabetic neuropathy.

\section{Subjects, methods, and results}

We included 20 patients in the investigation, but five dropped out because of compliance or personal problems. The remaining 15 patients (six women, nine men; median age 47 years, range 26-63) had had moderate or severe symmetrically painful diabetic neuropathy for from six months to 20 years (median three years). They all had more than one of the following symptoms: dull aching or lancinating pain, cutaneous dysaesthesia, numbness and tingling paraesthesia, nightly exacerbation of symptoms, and disturbed sleep. ${ }^{1}$ None of the patients suffered from alcohol abuse, cobalamin (vitamin $B_{12}$ ) deficiency, uraemia, cardiac or hepatic dysfunction, intermittent claudication, or infections. All patients gave informed consent, and the investigation was approved by the local ethical committee.

With an interval of five weeks the patients randomly received intravenous infusion of lidocaine $(5 \mathrm{mg} / \mathrm{kg}$ body weight) and isotone sodium chloride $(1 \mathrm{ml} / \mathrm{kg}$ body weight) over 30 minutes under continuous electrocardiographic monitoring. No side effects were noted. The patients did not use analgesics during the investigation.

The symptoms and signs of neuropathy were evaluated immediately before and after, the day after, and once weekly for five weeks after each infusion. A five item symptom score scale was used: pain, dysaesthesia, paraesthesia, nightly exacerbation, and disturbed sleep were each graded as absent (0), mild (1), moderate (2), or severe (3). From three days before and during the entire investigation the patients registered twice daily their degree of pain on a graphic visual analogue rating scale graded $0-100 \mathrm{~mm}$. To consider only the significant relief of pain with lidocaine and to reduce the influence of daily variation, the score for pain was calculated every three days, and only a reduction in score greater than $15 \mathrm{~mm}$ after infusion was considered to be an improvement. Serum lidocaine concentration and its metabolite monoethylglycinexylidide were determined at the end of each infusion. Statistical analyses were performed using Wilcoxon's test for paired differences, McNemar's test, and Spearman's rank correlation test.

Five item symptom score before and after lidocaine and placebo infusion in 15 patients with painful diabetic neuropathy. (Figures are medians with range in parentheses)

\begin{tabular}{lcc}
\hline & Lidocaine infusion & Placebo infusion \\
\hline Before treatment & $12(3-15)$ & $12(5-15)$ \\
Day 1 & $3^{\star}(0-15)$ & $6(0-13)$ \\
Day 8 & $5^{\star \star(15-15)}$ & $12(0-13)$ \\
Day 15 & $6^{\star \star \star(3-15)}$ & $12(2-15)$ \\
Day 22 & $12(2-15)$ & $11(0-15)$ \\
\hline
\end{tabular}

${ }^{\star} \mathrm{p}<0.05 ;{ }^{\star \star} \mathrm{p}<0.02 ;{ }^{\star \star \star} \mathrm{p}<0.10$

With the five item symptom score scale, lidocaine relieved symptoms significantly more effectively than the placebo one and eight days after infusion $(p<0.05$ and $p<0.02$, respectively) (table). In the 11 subjects who responded the effect of lidocaine lasted 3-21 days. With the visual analogue rating scale, 11 subjects showed reduced pain the first three days after lidocaine compared with four after the placebo $(p<0.05)$

Blood glucose, glycosylated haemoglobin, and body weight were identical immediately before the two infusions. There was no significant correlation between the reduction in symptoms or pain and the serum lidocaine and monoethylglycinexylidide, blood glucose, and glycosylated haemoglobin concentrations. Lidocaine had no significant influence on plantar, ankle, or knee reflexes, sensibility for touch and pain, sense of position, stereognosis, the vibration threshold at the big toe, beat to beat variation in heart rate during deep breathing, or response to postural blood pressure.

\section{Comment}

Treatment of painful diabetic neuropathy is a clinical problem and often disappointing. We round that intravenous lidocaine infusion significantly relieved symptoms in 11 of 15 patients with long term, painful diabetic neuropathy. An improvement in metabolic regulation cannot explain the findings. ${ }^{2}$ Lidocaine might relieve symptoms, as in cardiac arrhythmias, by disconnecting abnormal nervous impulse circuits.

Jens Kastrup received a research fellowship from the Univesity of Copenhagen.

1 Thomas PK, Wurd JD, Watkins PJ. Diabetic neuropathy. In: Keen H, Jarrett J, eds. Complications of diabetes. 2nd ed. London: Edward Arnold Ltd, 1982:109-36.

2 Anonymous. Pain perception in diabetic neuropathy [Editorial]. Lancet 1985;i:83-4.

Kvinesdal B, Molin J, Froland A, Gram LF. Imipramine treatment of painful diabetic neuropathy. JAMA 1984;251:1727-30.

4 Boas RA, Covino BG, Shahnarian A. Analgesic responses to intravenous lignocaine. Br $\mathcal{F}$ Anaesth 1982;54:501-5.

5 Edwards WT, Habib F, Burney RG, Begin G. Intravenous lidocaine in the management of various chronic pain states. A review of 211 cases. Regional Anaesth 1985;10:1-6.

(Accepted 28 October 1985)

Departments of Clinical Physiology and Nuclear Medicine and Clinical

Chemistry, Bispebjerg Hospital, DK 2400 Copenhagen NV, Denmark

JENS KASTRUP, MD, research fellow in diabetology

HELLE R ANGELO, PHD, pharmacist

Department of Neurology, Rigshospitalet, Copenhagen

PALLE PETERSEN, MD, medical registrar

Hvidøre Hospital, Klampenborg, Denmark

ANDERS DEJGÅRD, MD, medical registrar

Department of Medicine F, Glostrup Hospital, Copenhagen

JANNIK HILSTED, MD, medical registrar

Correspondence to: Dr Kastrup.

\section{Correction}

Clinical diagnosis of intracranial haemorrhage using Guy's Hospital score

We regret that there was an omission in this article by Dr P A G Sandercock $e$ al (14 December 1985, p 1675). In the fifth paragraph of the Patients and methods, on the diagnostic score for each patient, apoplectic onset should have been defined by the presence of any two of loss of consciousness at onset, headache within two hours, neck stiffness, and vomiting within six hours. 